The Impact of Public Health

Interventions on The First and

Second Waves of COVID-19 in

Trinidad And Tobago-A Simple

\section{Epidemic Model}

\author{
Loren De Freitas ${ }^{1}$, Han-I Wang ${ }^{2}$ \\ ${ }^{1}$ Arima District Health Facility, North Central Regional \\ Health Authority, Trinidad and Tobago \\ ${ }^{2}$ Mental Health and Addiction Research Group, \\ Department of Health Sciences, University of York, UK
}

\section{Corresponding Author:}

Dr. Loren De Freitas

Arima District Health Facility,

North Central Regional Health Authority

Trinidad and Tobago

Email: lorendefreitas@gmail.com

DOI: $10.48107 / C M J .2020 .12 .007$

\section{Copyright:}

\section{(c) (i)}

This is an open access article under the terms of the Creative Commons Attribution License which permits use, distribution and reproduction in any medium, provided the original work is properly cited.

\section{ABSTRACT}

\section{Introduction}

The COVID-19 pandemic has resulted in more than 35 million confirmed cases worldwide. Currently, there is no specific treatment for the disease or available vaccine to reduce the spread of COVID-19. As such, countries rely on a range of public health interventions to assist in halting the spread of transmission. Caribbean countries have also adopted many public health interventions. In this paper, we use mathematical modelling to demonstrate the impact of public health interventions on the progression of COVID-19 in order to provide timely decision support.

\section{Methods}

A cohort Markov model, based on the concept of the SEIR model, was built to reflect the characteristics of the COVID-19 virus. Five possible public health interventions in the first wave and a projection of current second wave were simulated using the constructed model.

\section{Results}

The model results indicate that the strictest combined interventions of complete border closure and lockdown were the most effective with the number of deaths less than ten in the first wave. For the current second wave, it will take around 30 days for the pandemic to pass its peak after implementing the wearing of face masks policy.

\section{Conclusions}

This paper shows the impact of common public health interventions on the COVID-19 pandemic, using Trinidad and Tobago as an example. Such impacts may be useful in reducing delays in decision-making and improving compliance by populations. However, given the limitations associated with mathematical models, decision-making should be guided by economic assessments, infectious disease and public health expertise.

Keywords: public health, COVID-19, mathematical model, Caribbean 


\section{INTRODUCTION}

The novel coronavirus, called SARS-CoV-2, has now resulted in a pandemic causing the disease COVID-19. ${ }^{1}$ The number of confirmed cases globally has surpassed 35 million with more than $1,000,000$ deaths. ${ }^{1}$ The first case of COVID-19 was confirmed in the Caribbean region on March $1^{\text {st }} 2020 .^{2}$ To date (October $\left.12^{\text {th }} 2020\right), 33$ Caribbean countries have registered cases with over 200,000 confirmed cases and almost 4000 deaths in the region. $^{3}$

The high transmissibility of the COVID-19 virus, its subsequent potential to quickly overwhelm a country's health system, the lack of treatment and an available vaccine creates an extremely uncertain situation. As such, many countries rely on the implementation of public health interventions as an approach to slow the spread of the disease. These public health interventions include border closures, school closures, social distancing measures such as reducing crowding, mass gatherings, physical distancing and health-related behavioural modifications such as hand washing, cough/sneeze etiquette and wearing of face masks. ${ }^{4,5}$

Caribbean countries have adopted similar approaches, implementing a range of interventions including border control and the most extreme form of social distancing, lockdowns. ${ }^{6}$ Knowledge of the potential impact of the interventions may reduce delays in implementation by decision makers and promote compliance by the public. In order to demonstrate such impacts, we used the example of Trinidad and Tobago, a Caribbean country with a population of approximately 1.3 million people, ${ }^{7}$ to construct a simple epidemic and strategy model based on the demographics of Trinidad and Tobago and the characteristics of the COVID-19 virus. This paper aims to discuss how public health interventions impacted the progression of COVID-19 in both first and second waves, using the simple epidemic model to highlight key areas. The purpose of the model is to demonstrate the magnitude of disease spread and the importance of public health interventions rather than to predict the actual number of confirmed cases and deaths.

\section{METHODS}

\section{Epidemic and strategy model}

The model was built based on the concept of the SEIR (Susceptible, Exposed, Infectious, Recovered) model and the specific characteristics of COVID-19 using the Markov model technique. The Markov model contained six health states and used a simulated cycle length of 1 day for the time horizon of one year. This simple Markov model was developed in Microsoft Excel (Microsoft Office Professional Plus $2010^{\odot} 2010$ Microsoft Corporation).

Figure 1 shows the model structure. The model starts with the pattern of imported cases: detected and undetected cases at the airport. Those people who enter the country undetected (including both symptomatic and asymptomatic) will enter the community and start transmitting the disease. Undetected symptomatic cases may eventually require medical attention as the disease progresses. This may result in different attack (reproduction number), recovery and mortality rates compared to asymptomatic cases. Those people who are detected at the airport or who are positively confirmed after seeking medical attention, will be quarantined and

\section{Figure 1. Model Structure}

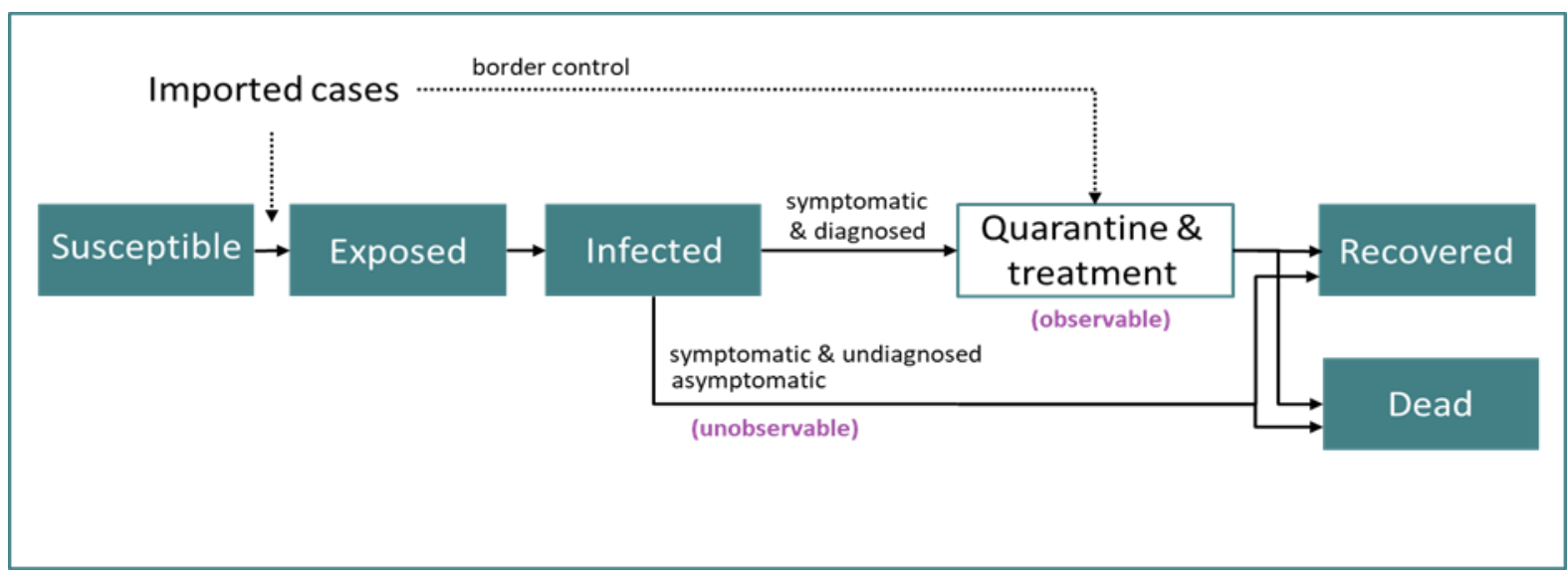


treated which should stop disease transmission to others.

In order to demonstrate the impact of public health interventions, several intervention scenarios were explored: (1) unmitigated epidemic, (2) airport control, (3) social distancing, (4) lockdown, (5) complete border closure on Day 30, (6) complete border closure on Day 30 and lockdown. In an unmitigated epidemic, no interventions are implemented and, as such, this scenario represents a worst-case situation. Airport control refers to the screening, isolation and quarantining of suspected individuals on arrival to a country while complete border closure represents a complete closure of airports and other borders resulting in no entry into a country.

A projection of the second wave is also presented. A second wave refers to an unexpected increase in cases under the current border closure policy. During the second wave in Trinidad and Tobago, an additional public health intervention was implemented- mandatory wearing of face masks. Based on the government statistics, we calibrated the model to project the impacts of the implemented restrictions from the first wave, as well as mandatory face mask wearing, from $3^{\text {rd }}$ September $2020 .^{8,9}$

The model was informed by various sources: published literature, up-to-date government statistics and best available evidence. Details of the variables used to populate the model are presented in Table $1 .{ }^{10-22}$ All the percentage information were transformed to rates (cases per day) before inserting them into the model.

The basic equations for the core SEIR model used in our model are listed below.

$$
\begin{gathered}
S_{n}=S_{n-1}-\left(\left(S_{n-1} / S\right) \times\left(\beta \times I_{n-1}\right)\right) \\
E_{n}=E_{n-1}+\left(\left(S_{n-1} / S\right) \times\left(\beta \times I_{n-1}\right)\right)-\left(\gamma \times E_{n-1}\right) \\
I_{n}=I_{n-1}+\left(\gamma \times E_{n-1}\right)-\left(I_{n-1} \times \alpha\right) \\
R_{n}=R_{n-1}+\left(I_{n-1} \times \alpha\right)
\end{gathered}
$$

$S$ notes susceptible individuals, exposed individual noted

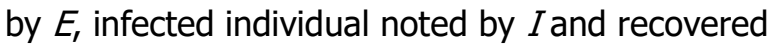
individuals noted by $R$. The equations calculated the number of people in each health state today $(n)$ based on the number yesterday $(n-1)$ and the rates of change such as $a, \beta$ and ${ }^{V}$, where $a$ is the rate of recovery, $\beta$ is the rate of infection and ${ }^{\gamma}$ is the reverse of incubation period. The above-mentioned equations were implemented in Excel and the cohort were moved from a state to another followed the standard process described by Briggs. ${ }^{23}$

For simplicity, several assumptions were made about the model. These include the following:

1. A well-mixed society.

2. The reproduction number, detection rate and transition rates were constant.

3. There were unlimited healthcare resources.

4. Those who are quarantined would not infect others including the medical staff and their families.

5. There was no contact tracing policy and the border remained opened.

\section{RESULTS}

\section{Impact of public health interventions on spread of disease}

The model results demonstrate the impact of interventions once there is community transmission. In the baseline scenario, no public health interventions were implemented in the country and the border remained open. This is considered an unmitigated epidemic or worst-case scenario. In this scenario, the number of confirmed cases increased steadily as a result of the border remaining open in the country, with approximately 650 confirmed cases and 20 deaths on Day 60.

The impact of the implemented public health interventions on the number of infected cases and deaths in symptomatic and diagnosed cases is demonstrated in Figure 2, graphs A and C, respectively. As shown, airport control resulted in a decreased number of deaths but the interventions related to decreasing reproduction number, such as social distancing, complete border closure and lockdown are even more effective. With the strictest combined interventions of complete border closure and lockdown, the curve of confirmed cases is almost flattened and the numbers of deaths were less than ten.

Aside from the confirmed cases, undiagnosed infected cases also exist. These included those persons who were asymptomatic and those who were symptomatic but did not require or seek medical attention. These persons may not be officially recorded and as a result may transmit 
Table 1: Parameters used to build the epidemic and strategy model

\begin{tabular}{|c|c|c|c|}
\hline & Value & Source & Note \\
\hline \multicolumn{4}{|l|}{ Rate of imported cases } \\
\hline $\begin{array}{l}\text { Number of actual detected cases at the air- } \\
\text { port from } 1 \text { March to } 1 \text { April }\end{array}$ & 90 & $(10)$ & \\
\hline Detect rate at the airport & 0.6 & assumption & \\
\hline \multicolumn{4}{|l|}{ Model parameters } \\
\hline $\mathrm{S}=$ initial number of susceptible population & 1363985 & $(11)$ & \\
\hline $\begin{array}{l}\mathrm{E}=\text { incubation period (from exposure to } \\
\text { transmission) }\end{array}$ & 5 & 12) & \\
\hline $\mathrm{R} 1=\mathrm{R}_{0}$ for asymptomatic cases & 1.64 & (13) & Assume to be half of R3 \\
\hline $\begin{array}{l}\text { R2 = } R_{0} \text { for symptomatic and undiagnosed cas- } \\
\text { es }\end{array}$ & 1.64 & $(13)$ & Assume to be the same as R1 \\
\hline $\mathrm{R} 3=\mathrm{R}_{0}$ for symptomatic and diagnosed cases & 3.28 & $(14)$ & \\
\hline $\begin{array}{l}\text { a1 = recovery rate for asymptomatic cases / } \\
\text { day }\end{array}$ & 0.06 & $(15)$ & $\begin{array}{l}\text { Mean duration of infection: } 17 \\
\text { day }\end{array}$ \\
\hline $\begin{array}{l}\text { a2 = recovery rate for symptomatic and undi- } \\
\text { agnosed cases / day }\end{array}$ & 0.06 & $(15)$ & Assume to be the same as a1 \\
\hline $\begin{array}{l}\text { a3 = recovery rate for symptomatic, diagnosed } \\
\text { and non-hospitalised cases / day }\end{array}$ & 0.07 & $(16)$ & $\begin{array}{l}\text { Mean duration of infection: } 14 \\
\text { days }\end{array}$ \\
\hline $\begin{array}{l}\text { a4 = recovery rate for symptomatic, diagnosed } \\
\text { and hospitalised cases / day }\end{array}$ & 0.05 & (17) & $\begin{array}{l}\text { Mean duration of infection: } 20 \\
\text { days }\end{array}$ \\
\hline D1 = Mortality for asymptomatic cases & $3.5 \%$ & $(18)$ & Assume to be the same as D3 \\
\hline $\begin{array}{l}\text { D2 = Mortality for symptomatic and undiag- } \\
\text { nosed cases }\end{array}$ & $3.5 \%$ & $(18)$ & Assume to be the same as D3 \\
\hline $\begin{array}{l}\text { D3 = Mortality for symptomatic, diagnosed and } \\
\text { non- hospitalised cases }\end{array}$ & $3.5 \%$ & $(18)$ & \\
\hline $\begin{array}{l}\text { D4 = Mortality for symptomatic, diagnosed and } \\
\text { hospitalised cases }\end{array}$ & $28 \%$ & $(17,19)$ & \\
\hline B1 = percentage of asymptomatic cases & 0.178 & $(20)$ & \\
\hline $\begin{array}{l}\text { B2 = percentage of symptomatic cases diag- } \\
\text { nosed }\end{array}$ & 0.55 & (21) & \\
\hline $\begin{array}{l}\text { B3 = percentage of symptomatic and diag- } \\
\text { nosed cases requiring hospitalisation }\end{array}$ & 0.32 & $(22)$ & \\
\hline $\begin{array}{l}\text { B4 = Mean days from exhibiting symptoms to } \\
\text { seeking medical assistance }\end{array}$ & 5 & (13) & \\
\hline \multicolumn{4}{|l|}{ Scenarios } \\
\hline Border control & $A=0.8$ & assumption & \\
\hline Social distancing & $\mathrm{R}_{0} * 0.8$ & assumption & \\
\hline Complete lockdown & $\mathrm{R}_{0} * 0.6$ & assumption & \\
\hline $\begin{array}{l}\text { Second wave under implemented } \\
\text { restrictions }\end{array}$ & $\mathrm{R}_{0}=1$ & assumption & \\
\hline
\end{tabular}


disease within the community. Figure 2, graphs B and D, shows the impact of the implemented public health interventions on the number of infected cases and deaths respectively in this undiagnosed but infected group of persons, which we term 'silent' cases. As shown, the social distancing, complete border closure and lockdown interventions appear to be as effective in controlling the spread of disease in these 'silent' cases, with the combined interventions of complete border closure and lockdown remaining as the most effective intervention.

In the second wave model, the model was able to reproduce the number of confirmed cases and deaths which were found to be similar to the actual reported figures for the first 30 days (Figure 3 ). The estimated increased number of confirmed cases from $3^{\text {rd }}$ September to $3^{\text {rd }}$ October was around 2,600 (2,731 confirmed based on national reports) and the increased number of deaths was around 75 (less than 70 based on confirmed national reports). ${ }^{24}$ If this trend continues with no unexpected imported cases and the same restrictions remain implemented, it is theoretically possible that the local spread will be at a negligible level in early 2021 (Figure 3).

\section{DISCUSSION}

\section{Public health interventions and potential challenges}

In this paper, we used Trinidad and Tobago as an example to demonstrate the impact of public health interventions on the spread of COVID-19. The model results showed that various interventions have different levels of impact on the numbers of confirmed cases and deaths. Compared to the unmitigated epidemic (worst case scenario), the strictest combined interventions of complete border closure and lockdown produced the least number of confirmed cases and deaths. Such

\section{Figure 2. Model results showing the impact of public health interventions}
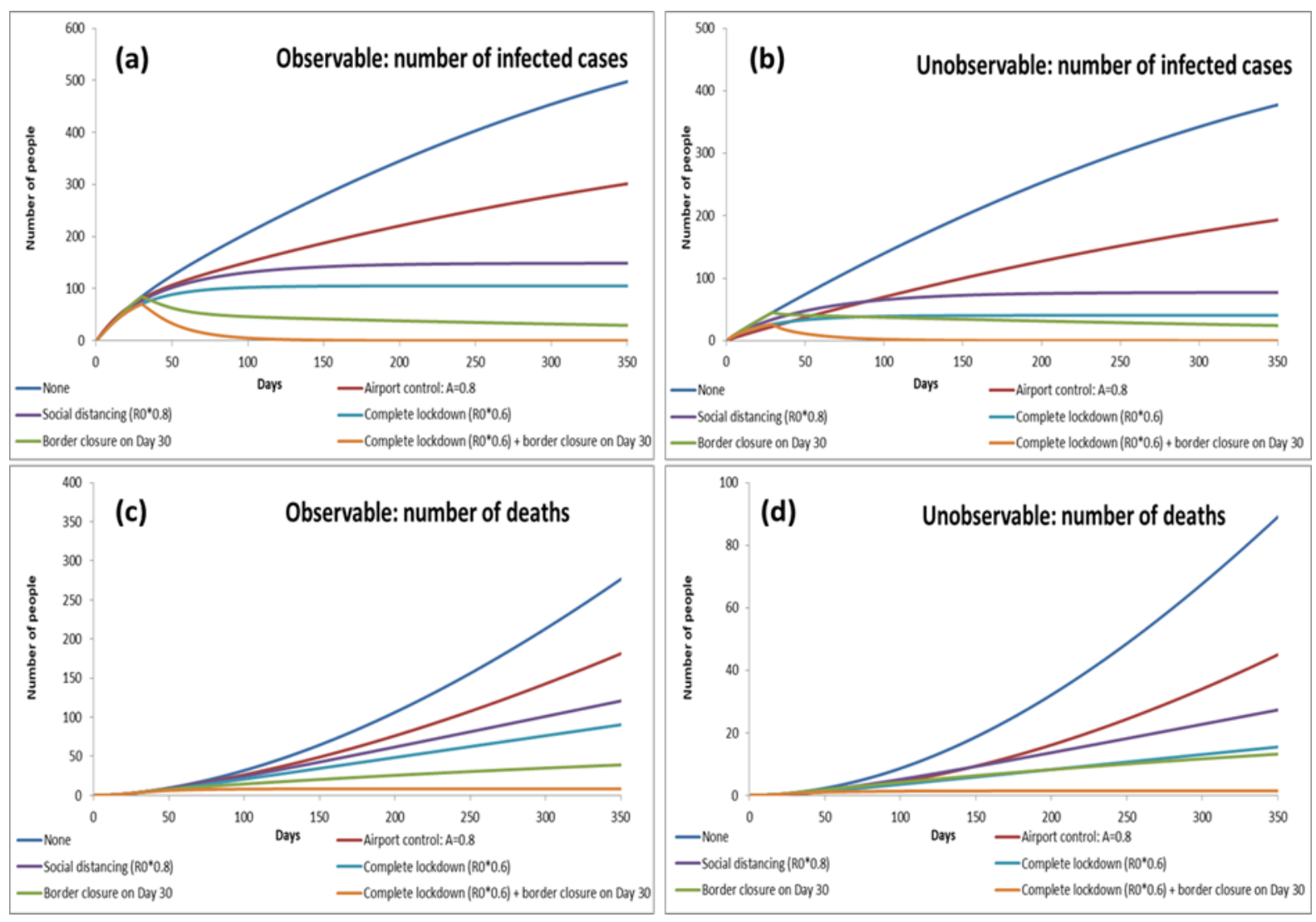

Key:

'observable' = 'symptomatic and diagnosed'

'unobservable' = symptomatic, undiagnosed, asymptomatic 


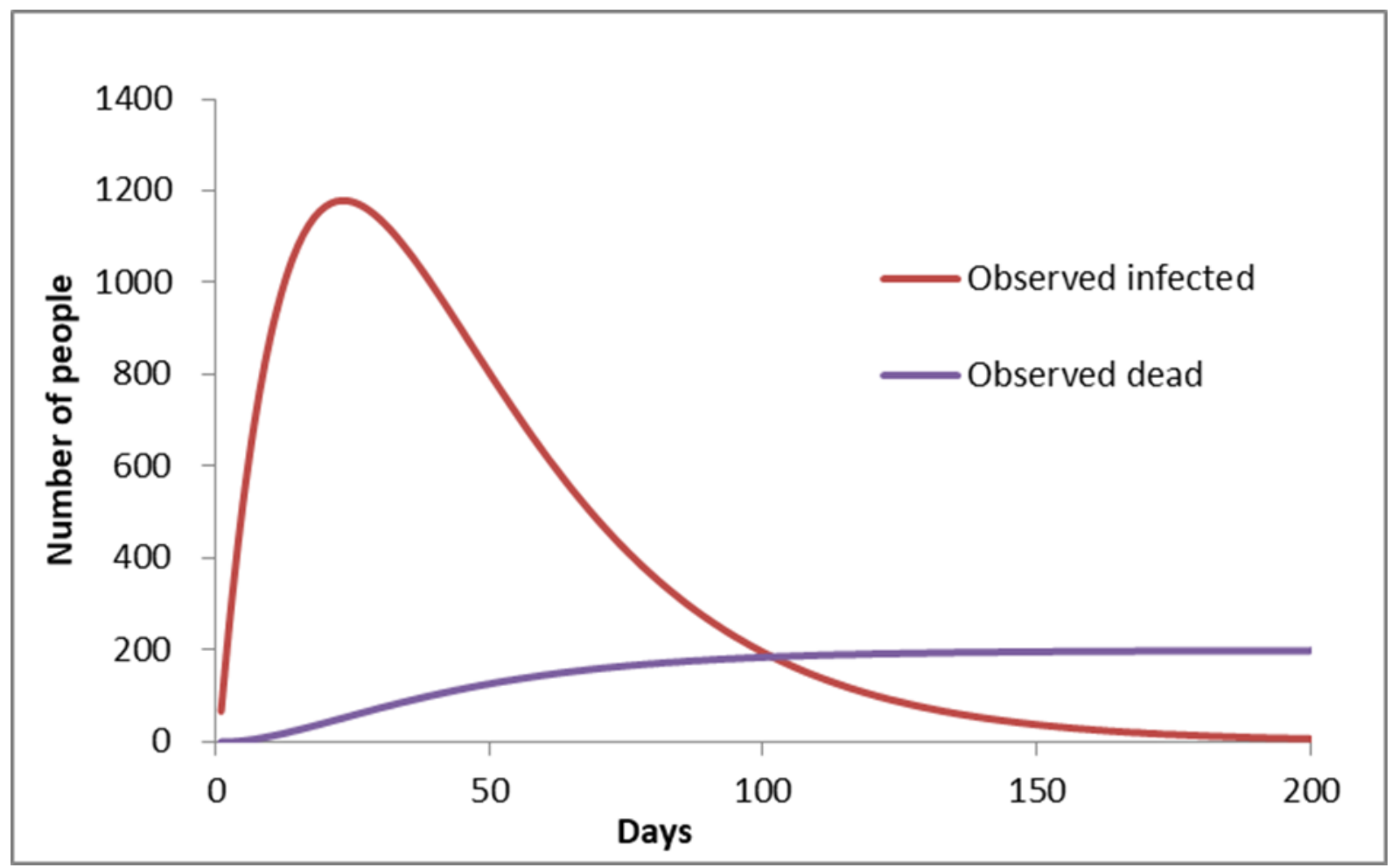

Key: 'observed'= 'symptomatic and diagnosed'

effectiveness of interventions can also be observed in the real-world settings in the initial phase of the pandemic. ${ }^{25}$

In many Caribbean countries, a phased border closure approach was used as an option to minimise imported cases. As the pandemic progressed, non-essential travel was limited and eventually a complete border closure was implemented, which included restricting entry to citizens. ${ }^{26}$ The complete border closure intervention is considered to be very effective, as seen in the first wave of the pandemic in Trinidad and Tobago (from April to July). The effectiveness was mirrored in our hypothetical model where the complete border closure on Day 30 appeared to be the second most effective intervention after the combination of complete lockdown and border closure (on both symptomatic and asymptomatic cases). However, despite the apparent effectiveness on controlling the spread of the disease, the timing and the level of the border closure remains a challenge to decision and policy makers. Political and economic concerns may influence the decision to close a country's borders. If borders are open then strict screening and quarantine measures at the border (both air and sea) may be required.
Given the challenges surrounding border closures, a more timely and practical measure may be considered, for example, the use of information technology. With careful planning, information technology may be implemented and used in various avenues such as contact tracing and public health education. ${ }^{25-6}$ This method allows for the identification and monitoring of high-risk individuals through data linkage among border control, medical records, CCTV footage and cellular providers. However, this use of technology will also need to be balanced between privacy laws and public health strategies. ${ }^{27}$

Real-time public communication, another form of information technology, may also be used for public health education purposes. ${ }^{25,27}$ This strategy has shown that delivering simple and vital health education information using SMS text messages can provide the public with effective guidance for prevention of COVID19 , assisting with the location of nearby testing centres and combatting misinformation. ${ }^{27-8}$

Without an available vaccine, widespread testing and surveillance of populations is also considered an option for controlling the spread of disease from those who are undiagnosed or asymptomatic. ${ }^{29}$ Such interventions may 
allow governments to identify these 'silent' infected individuals and subsequently apply corresponding interventions to stop/break the chain of transmission. The importance of managing and controlling 'silent' cases is demonstrated in Figure 2 with the public health interventions resulting in low numbers of deaths and infections. However, widespread testing and surveillance of populations is also not without its limitations. ${ }^{29,30}$ The financial burden of widespread testing may be an issue as such an initiative requires manpower, sufficient personal protective equipment and testing kits, all of which are currently limited. ${ }^{30} \mathrm{~A}$ more effective and efficient intervention may be rapid identification of clusters of cases or super-spreaders through contact tracing. ${ }^{31}$

The wearing of face masks is another measure whose effectiveness is now supported by a growing body of evidence. ${ }^{32-3}$ Some early studies have suggested that wearing face masks can reduce the reproduction rate to less than one, suggesting that it is a relatively cheap (compared with widespread testing) and effective way to stop the spread of disease. ${ }^{8,9}$ Trinidad and Tobago supported the use of face masks early in the first wave of the pandemic and in the second wave the country introduced it as a mandatory public health measure. Based on our model, it will take around 30 days for the disease to pass its peak after the implementation of the wearing of face masks policy (Figure 3). However, it is important to note that the face mask policy alone will not be responsible for managing the spread of disease; rather it is the combination of multiple public health measures in addition to cooperation and compliance from the public that contributes to any success.

Although many intervention options are useful in reducing disease transmission, the challenge for many Caribbean countries, as with many countries globally, is identifying which interventions to implement, which interventions should be combined and when interventions should be implemented. Different interventions will have different levels of effectiveness but the most effective choice may not always be the best option for decision makers. As many Caribbean islands rely on tourism to sustain their economies, stricter interventions such as complete border closure and lockdown may be damaging to their economies and may not form part of a sustainable plan for managing the disease. ${ }^{34}$ Therefore, a balancing act between public health and economics is required to meet the demands of developing health systems and vulnerable economies in the region.

Our hypothetical model is simple and may be useful for supporting decision making, as it provides a quick view of disease spread and demonstrates the possible impacts of certain public health interventions in Trinidad and Tobago. However, our model results need to be interpreted with caution, as there are limitations. The model may over-simplify the reality as the parameters used were based on data and evidence from the early phases of the pandemic. Importantly, it does not take in to account human and behavioural factors. -This includes factors such as institutional trust and confidence, belief in misinformation and perceived risk. If individuals do not perceive that there is a risk of contracting the disease, they may be less likely to seek health care (eg. get tested) or cooperate with health professionals (eg. effective contact tracing relies on individuals being forthcoming with information). ${ }^{[35]}$ Since these behavioural factors were not taken into account in our model, this may affect the projected impact of interventions.

In order to provide decision makers with more reliable information to support informed decisions, a more comprehensive epidemiology and strategy model (compared to our hypothetical model) is required. This model should (1) take into account the local geography and human mobility patterns, (2) consider the structure of the medical system and healthcare resources available, (3) combine public health strategy and economic assessment, (4) predicate the impact of interventions on the trajectory of a disease. Such models should also be accompanied by studies that explore behavioural factors. Altogether, this should assist complex pandemic planning.

\section{CONCLUSION}

In conclusion, this paper shows the impact of common public health interventions on the COVID-19 pandemic in Trinidad and Tobago, using a simple epidemic model. Pandemic planning and response is a complex process. Decisions regarding effectiveness of interventions to limit the spread of disease should be guided by the use of reliable epidemiology models, economic assessments, behavioural studies, infectious disease and public health expertise in order to manage this pandemic as well as future pandemics. 


\section{DECLARATIONS}

Competing interests: None

Funding: None

Ethical approval: Not required

Availability of data and materials: All data and material used in this paper are in the form of published articles and weblinks. These are freely available online.

Authors' Contributions: LD conceptualised the idea. HW created the models. LD and HW drafted the article and both authors contributed to the final version of the submitted article. All authors read and approved the final manuscript for submission.

\section{REFERENCES}

1. World Health Organisation. Coronavirus disease (COVID-19) Pandemic, 2020.

2. https://www.worldometers.info/coronavirus/country/ trinidad-and-tobago/ (Accessed 12/10/ 2020)

3. Caribbean Public Health Agency. Coronavirus Disease (COVID-19), 2020 https://carpha.org/What-We-Do/ Public-Health/Novel-Coronavirus (Accessed 12/10/2020)

4. Caribbean Public Health Agency. Coronavirus Disease (COVID-19). Situation Report 45. https://carpha.org/ What-We-Do/Public-Health/Novel-Coronavirus (Accessed 1/10/2020)

5. Imai N, Gaythorpe KAM, Abbott S et al. Adoption and Impact of non-pharmaceutical interventions for COVID-19. Wellcome Open Research [internet]. 2020. Available from: https:// wellcomeopenresearch.org/articles/5-59

6. Smith SMS, Sonego S, Wallen GR et al. Use of nonpharmaceutical interventions to reduce transmission of influenza in adults: a systematic review. Respirology [internet]. 2015;20(6): 896-903. Available from: https://www.ncbi.nlm.nih.gov/pmc/ articles/PMC4699551/

7. Government of the Republic of Trinidad and Tobago Ministry of Health. COVID-19 Novel Coronavirus, 2020 http://www.health.gov.tt/sitepages/ default.aspx?id=293 (Accessed 28/09/2020)

8. Government of Trinidad and Tobago. Central Statistical Office. Population https://cso.gov.tt/ subjects/population-and-vital-statistics/population/ (Accessed 26/09/2020)

9. Fisman DN, Geer AL, Tuite AR. Bidirectional impact of imperfect mask use on reproduction number of COVID-19: A next generation matrix approach. Infectious Disease Modelling. 2020; 5:405-408. https://www.ncbi.nlm.nih.gov/pmc/articles/ PMC7334658/ (Accessed 10/10/2020)

10. Stutt ROH, Retkute R, Bradely M. A modelling framework to assess the likely effectiveness of facemasks in combination with 'lock-down' in managing the COVID-19 pandemic. Proceedings of the Royal Society. 2020: 476. https:// royalsocietypublishing.org/doi/10.1098/ rspa.2020.0376 (Accessed 10/10/2020)

11. Trinidad and Tobago Coronavirus:- Worldometer https://www.worldometers.info/coronavirus/country/ trinidad-and-tobago/ (Accessed 10/10/2020)

12. Mid Year Estimates of Population by Age Group. Central Statistical Office; https://cso.gov.tt/ cso_statistics/mid-year-estimates-of-population-byage-group/ (Accessed 10/10/2020)

13. Lauer $\mathrm{SA}$, Grantz $\mathrm{KH}, \mathrm{Bi} \mathrm{Q}$ et al. The Incubation Period of Coronavirus Disease 2019 (COVID-19) From Publicly Reported Confirmed Cases: Estimation and Application. Annals of Internal Medicine. 2020 May 5;172(9):577-82. https://www.ncbi.nlm.nih.gov/ pmc/articles/PMC7081172/ (Accessed 13/10/2020)

14. Ferguston N, Laydon D, Nedjati-Gilani, G, et al. Report 9: Impact of non-pharmaceutical interventions (NPIs) to reduce COVID-19 mortality and healthcare demand. Imperial College London; 2020 Mar http://www.imperial.ac.uk/medicine/ departments/school-public-health/infectious-diseaseepidemiology/mrc-global-infectious-disease-analysis/ covid-19/report-9-impact-of-npis-on-covid-19/ (Accessed 13/10/2020)

15. Liu Y, Gayle AA, Wilder-Smith A et al. The reproductive number of COVID-19 is higher compared to SARS coronavirus. Journal of Travel Medicine. 2020 13;27(2). https:// pubmed.ncbi.nlm.nih.gov/32052846/ (Accessed 13/10/2020)

16. Luo S-H, Liu W, Liu Z-J et al. A confirmed asymptomatic carrier of 2019 novel coronavirus. Chinese Medical Journal (Engl). 2020 May 5;133 (9):1123-5. https://journals.Iww.com/cmj/ 
fulltext/2020/05050/

a_confirmed_asymptomatic_carrier_of_2019_novel.2

1.aspx (Accessed 13/10/2020)

17. World Health Organisation. Report of the WHO-China Joint Mission on Coronavirus Disease 2019 (COVID19). 2020. Available from: https:// www.who.int/docs/default-source/coronaviruse/whochina-joint-mission-on-covid-19-final-report.pdf (Accessed 28/09/2020)

18. Gaythorpe K, Imai N, Cuomo-Dannenburg G et al. Report 8: Symptom progression of COVID-19. Imperial College London; 2020. http:// spiral.imperial.ac.uk/handle/10044/1/77344 (Accessed 12/10/2020)

19. World Health Organisation. Coronavirus disease 2019 (COVID-19) Situation Report - 46; 2020 https:// www.who.int/docs/default-source/coronaviruse/ situation-reports/20200306-sitrep-46-covid-19.pdf? sfvrsn=96b04adf_4 (Accessed 15/09/2020)

20. Weiss $P$, Murdoch DR. Clinical course and mortality risk of severe COVID-19. The Lancet. 2020 Mar 28;395(10229):1014-5. https://www.thelancet.com/ article/S0140-6736(20)30633-4/fulltext (Accessed 13/10/2020)

21. Lee BY. Study: $17.9 \%$ Of People With COVID-19 Coronavirus Had No Symptoms Forbes. https:// www.forbes.com/sites/brucelee/2020/03/18/whatpercentage-have-covid-19-coronavirus-but-do-notknow-it/ (Accessed 01/10/2020)

22. Li R, Pei S, Chen B et al. Substantial undocumented infection facilitates the rapid dissemination of novel coronavirus (SARS-CoV-2). Science. 2020 01;368 (6490):489-93. https://science.sciencemag.org/ content/368/6490/489 (Accessed 13/10/2020)

23. European Centre for Disease Prevention and Control. Coronavirus disease 2019 (COVID-19) in the EU/EEA and the UK. https://www.ecdc.europa.eu/sites/ default/files/documents/covid-19-rapid-riskassessment-coronavirus-disease-2019-eighth-update8-april-2020.pdf (Accessed 02/10/2020)

24. Briggs A, Sculpher M, Claxton K. Decision Modelling for Health Economic Evaluation. Oxford, UK: Oxford University Press, 2006.

25. Government of the Republic of Trinidad and Tobago Ministry of Health. COVID-19 Novel Coronavirus, 2020 http://www.health.gov.tt/sitepages/ default.aspx?id=310 (Accessed 13/10/2020)
26. Chen $L$, Yuan $X$. China's ongoing battle against the Coronavirus: Why did the lockdown strategy work so well? Socio-ecololgical Practice Research, 2020;15:16. https://www.ncbi.nlm.nih.gov/pmc/articles/ PMC7158267/ (Accessed 12/10/2020)

27. Caribbean Public Health Agency. Caribbean Countries. Prevention Measures, Travel Advisories and Reopening Plan. 2020 https://www.carpha.org/WhatWe-Do/Public-Health/Novel-Coronavirus/PreventionMeasures-Travel-Advisories-and-Reopening-Plan (Accessed 12/10/2020)

28. Wang CJ, Ng CY, Brook RH. Response to COVID-19 in Taiwan. Big Data Analytics, New Technology and Proactive Testing. Journal of American Medical Association. 2020;323 (14):1341-1342. https:// jamanetwork.com/journals/jama/fullarticle/2762689 (Accessed 11/10/2020)

29. World Health Organisation. ITU-WHO Information Technology Joint Statement: Unleasing information technology to defeat COVID-19, 2020. https:// www.who.int/news-room/detail/20-04-2020-itu-whojoint-statement-unleashing-information-technology-to -defeat-covid-19 (Accessed 15/09/2020)

30. Addi RA, Benksim A, Mohamed A et al. Asymptomatic COVID-19 infection management: the key to stop COVID-19. Journal of clinical and experimental investigation. 2020; 11(3).https:// www.jceionline.org/article/asymptomatic-covid-19infection-management-the-key-to-stop-covid-19-7866 (Accessed 03/10/2020)

31. Studdert DM, Hall MA. Disease control, civil liberties and mass testing-calibrating restrictions during the COVID-19 pandemic. New England Journal of Medicine. 2020; https://www.nejm.org/doi/ full/10.1056/NEJMp2007637 (Accessed 10/10/2020)

32. Organisation for Economic Cooperation and Development. Testing for covid-19: a way to lift confinement restrictions. May 2020. https:// www.oecd.org/coronavirus/policy-responses/testingfor-covid-19-a-way-to-lift-confinement-restrictions89756248/ (Accessed 12/10/2020)

33. Van der Westerhuisen $H$, Tonkin-Crine $S$, Greenhalgh T. Face coverings for covid-19: from medical intervention to social practice. British Medical Journal. 2020;370. https://www.bmj.com/content/370/ bmj.m3021 (Accessed 12/10/2020)

34. Worby $\mathrm{CJ}$, Chang $\mathrm{H}$. Face mask use in the general 
population and optimal resource allocation during the COVID -19 pandemic. Nature Communications.

2020;11: 4049. https://www.ncbi.nlm.nih.gov/pmc/ articles/PMC7426871/ (Accessed 12/10/2020)

35. Copenhagen Economics. Economic consequences of the COVID-19 pandemic. https://

www.copenhageneconomics.com/dyn/resources/

Publication/publicationPDF/0/530/1585835646/

copenhagen-economics_economic-consequences-

covid-19.pdf (Accessed 01/09/2020)

36. Vinck $P$, Pham PN, Bindu KK et al. Institutional trust and misinformation in response to the 2018-2019

Ebola outbreak in the North Kivu. DR Congo: a population based survey. The Lancet Infectious

Diseases.2019; 19(5): 529-536. https://

www.thelancet.com/journals/laninf/article/PIIS1473-

3099(19)30063-5/fulltext (Accessed 10/10/20200 